\title{
Serial changes in the head-shaft angle of proximal humeral fractures treated by placing locking plates: a retrospective study
}

\author{
Ji-Qi Wang ${ }^{\dagger}$, Bing-Jie Jiang ${ }^{\dagger}$, Wei-Jun Guo and You-Ming Zhao*
}

\begin{abstract}
Background: Although the proximal humeral fractures (PHFs) treated with locking plate have been well applied, there are few studies concerning on the serial HSA changes after locking plate placement. The purpose of this retrospective study was to explored the clinical significance of serial HSA changes after surgery.

Methods: We retrospectively analyzed the clinical data of 122 patients between January 2012 to December 2016 in our hospital. The serial change of the HSA and Neer's score of 122 patients were recorded and analyzed. Then, we evaluated the HSA changes affected functional recovery in conjunction with medial support (MS). Moreover, multivariable linear regression analysis was performed to identify any potential confounding factors that may influence functional recovery.

Results: Of 146 patients, 122 (50 males and 72 females) patients were finally enrolled in our study. Our preliminary data suggested that the most decrease of HSA occurred in the period of 1 to 3 months $(p<0.001)$ postoperatively, and functional recovery was significantly related with the change of HSA $\left(R^{2}=0.647, p<0.001\right)$. The presence of MS plays an important role in maintaining postoperative HSA and restoring function. Moreover, Neer type 4 fracture, the difference between the postoperative HSA (on the injured side) and that of the uninjured side (the $\triangle H S A$ ), and the HSA change to the end of follow-up were all significantly associated with functional recovery.

Conclusions: Serial HSA changes were evident in PHF patients in whom locking plates had been inserted; it is essential to maintain reduction for 1-3 months postoperatively. MS is important in this context and surgeons must maximally restore MS. Furthermore, the functional outcome tended to improve when the HSA of the injured side was restored to a value close to that of the uninjured side.
\end{abstract}

Keywords: Proximal humeral fractures, Locking plate, Head-shaft angle, Functional outcomes, Medial support

\section{Background}

Proximal humeral fractures (PHFs) represent $5 \%$ of all fractures [1] and require surgical treatment, especially in elderly patients for whom high-level functional recovery is important [2]. Placement of a proximal humeral internal locking system (PHILOS) is the current mainstay of treatment to achieve minimal loss of function [3]. Despite the advantages of this technique, the use of locking plates to surgically treat PHF is associated with high complication rates (16-

\footnotetext{
* Correspondence: wmuorthopaedic@sina.com

${ }^{\dagger} \mathrm{Ji}$-Qi Wang and Bing-Jie Jiang contributed equally to this work.

Department of Orthopaedics, The Second Affiliated Hospital and Yuying

Children's Hospital of Wenzhou Medical University, 109\# Xue Yuan Xi Road, Wenzhou, Zhejiang 325000, China
}

36\%) [4]. The major complications are reduction loss and varus malunion $[3,5,6]$; reduction loss can be associated with screw perforation of the articular surface, triggering a need for re-operation, or even causing complete fixation failure [7]. Recent studies showed that a lack of medial support (MS) might play an important role in reduction loss [8-10].

Generally, the humeral head-shaft angle (HSA) dictates the choice of plate length [11];our understanding of the HSA is continuously improving. To the best of our knowledge, the HSA is closely associated with shoulder function and is affected by many factors. However, only a few studies focused on serial HSA changes after locking plate placement. We explored the clinical 
significance of serial HSA changes after surgery. We retrospectively evaluated the changes, i.e. how they affected functional recovery in conjunction with MS, and the relationship between HSA changes and clinical outcomes after PHILOS fixation of PHFs.

\section{Methods}

\section{Study design}

We retrospectively reviewed serial HSA changes in PHF patients treated via locking plate placement. Our institutional ethics committee approved the study and all participants provided written informed consent prior to data collection.

\section{Patients}

The inclusion criteria were as follows: an acute closed fracture < 14 days old treated via PHILOS; age $\geq 18$ years; no complication such as nerve or vascular injury; no history of an upper extremity fracture; and complete follow-up. From January 2012 to December 2016, we treated 146 PHF patients using the PHILOS. Of these, 24 were excluded: 3 with open fractures, 3 with a history of upper extremity fracture, 4 with nerve injury, and 14 lost to follow-up. Thus, 122 patients (50 males and 72 females) met the inclusion criteria and were enrolled; we also measured the HSAs of the uninjured sides. According to the Neer classification [12], we treated 44 two-part, 58 three-part, and 20 four-part fracture patients.

\section{Surgical technique}

All patients underwent a standard procedure via a deltopectoral approach while in the beach-chair position. After confirming satisfactory reduction, fragments were temporarily fixed with K-wires. Next, appropriate locking proximal humeral plates (Proximal Humeral Inter-locking System; Synthes; Oberdorf, Switzerland) were used to fix the fractures.

All patients underwent similar postoperative rehabilitation; the shoulders were sling-immobilised for 3-6 weeks, followed by controlled passive mobilisation exercises (pendulum exercise, flexion, and external rotation) for 1-6weeks depending on fracture type and bone healing. For all patients, stretching and resistive strengthening exercises were recommended until complete fracture healing was evident on radiographs.

\section{Postoperative follow-up}

$\mathrm{X}$-rays were taken immediately after the operation; at $1,3,6$, and 12 months; and at the last follow-up. The HSA was measured as described by Agudelo et al. [13] (Fig. 1).A vertical line was first drawn from the superior to the inferior border of the articular surface

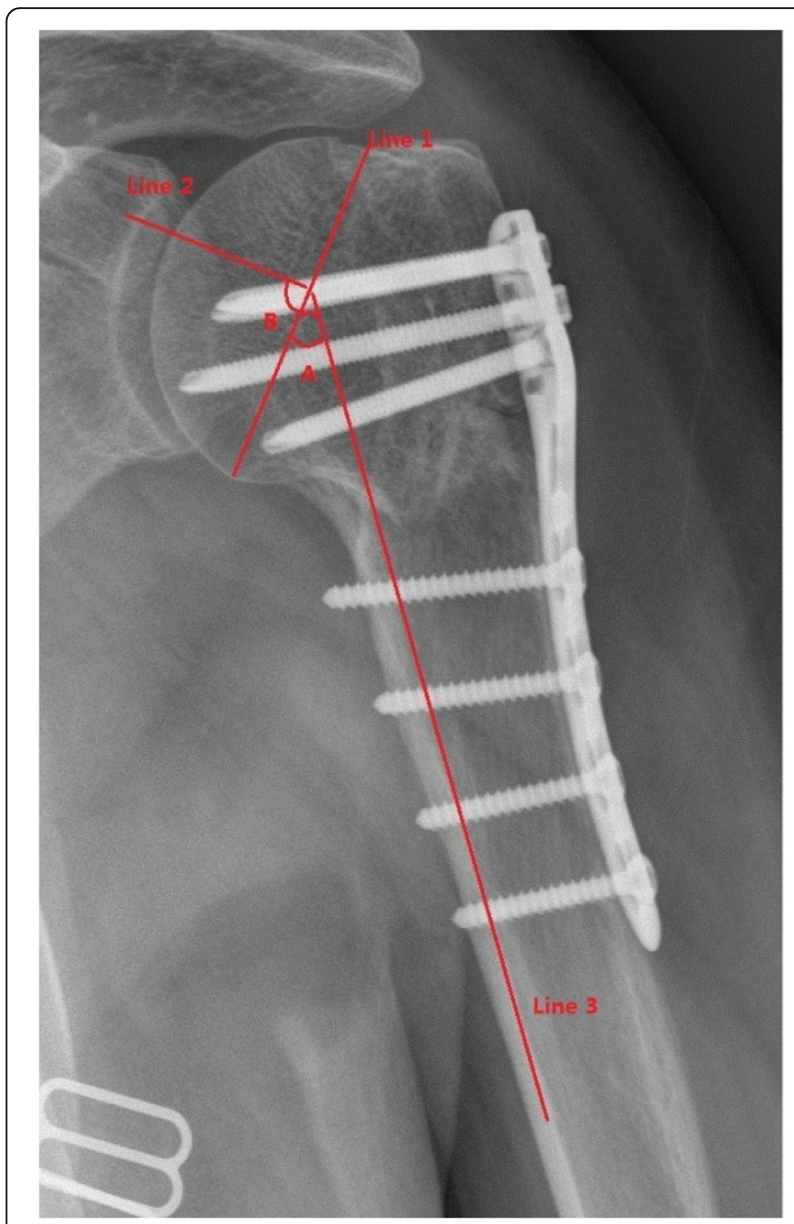

Fig. 1 The head-shaft angle (HSA) measurement method. A vertical line is drawn from the superior to the inferior border of the articular surface (Line 1) and a line perpendicular to this line is then drawn to run through the centre of the humeral head (Line 2). The angle between the latter line and a line parallel to the long axis of the humeral shaft (Line 3) is the humeral head-shaft angle. We found that this angle (angle B) was equal to the angle between the vertical and the long axes (angle A) plus $90^{\circ}$

(Line 1) and a line perpendicular to this line was then drawn through the centre of the humeral head (Line 2 ). The angle between the latter line and a line parallel to the long axis of the humeral shaft (Line 3) was defined as the humeral HSA. We found that this angle (angle B) was identical to the angle between the vertical and long axes (angle A), plus 90 $0^{\circ}$ HSAs were independently assessed (twice) by two reviewers blinded to the clinical outcomes; the average of each set of four values was used in the analysis. In addition, following the recommendation of Greiner [14], an $\mathrm{HSA}<120^{\circ}$ was considered indicative of varus malunion. Using the criterion of Owsley [15], loss of reduction was defined as an $\mathrm{HSA}$ reduction $>10^{\circ}$. 
Functional recovery was evaluated using the Neer criteria [16] at the last follow-up.

\section{Statistical analysis}

All statistical analyses were performed using SPSS software (ver. 19.0; SPSS Inc., Chicago, IL, USA). Numerical data were compared using Student's t-test. One-factor analysis of variance (ANOVA) was employed to compare group means, and the LSD test was used to perform multiple comparisons. The Kruskal-Wallis test was employed to compare differences in Neer scores during follow-up; multiple comparisons were performed with the Tamhane T2 test. Categorical data were compared using the chi-squared $\left(x_{2}\right)$ and Fisher's exact tests. We performed linear regression analysis to identify relationships between functional outcomes and HSA changes. Univariate analysis was employed to explore associations between various factors and the Neer scores; multivariable linear regression was then performed to control for confounding effects. The level of significance was set to 0.05 for all analyses.

\section{Results}

In total, 122 patients (50 males and 72 females) were included; their demographic data are listed in Table 1. The mean age was 61.1 years (range: $37-87$ years). Over a mean of 16.2 months of follow-up (range: 12-24 months), all patients achieved bony union; the mean healing time was 4.4 months (range: $3-12$ months). We treated 44 two-part, 58 three-part, and 20 four-part

Table 1 Patient's demographic information

\begin{tabular}{ll}
\hline Total patients & 122 \\
Male & 50 \\
Female & 72 \\
Age (year) & $61.1 \pm 12.3$ \\
Fracture type & \\
two-part & 44 \\
three-part & 58 \\
four-part & 20 \\
Healing time (months) & $4.4 \pm 1.3$ \\
Follow-up time (months) & $16.2 \pm 3.2$ \\
Uninjured side HSA ( ${ }^{\circ}$ & $136.5 \pm 4.8$ \\
Complications & \\
Reduction loss & 18 \\
Varus malunion & 16 \\
Subacromial impingement & 2 \\
Delayed union & 4 \\
Reoperation & 2 \\
\hline
\end{tabular}

HSA head-shaft angle fracture patients; the mean HSA of the uninjured side was $136.5 \pm 4.8^{\circ}$. Reduction loss was observed in 18 patients, of whom 16 experienced varus malunion, 2 subacromial impingement, 2 screw penetration requiring re-operations to remove the screws, and 4 delayed union that healed only after 12 months of follow-up.

We found that most of the HSA reduction occurred from 1 to 3 months postoperatively, and the reduction amount was $4.9 \pm 3.3^{\circ}(p<0.001$, Fig. 2$)$. We divided the patients into two groups: with and without MS. We found no significant difference in HSA loss between the groups at 1 month postoperatively. However, after 3 months, the HSA of patients with MS was significantly greater than that of patients without MS (Table 2). Figure 3 shows the HSA trends during follow-up. The Neer score of patients with MS was significantly higher than that of patients lacking MS; the former patients enjoyed better functional recovery. Also, patients lacking MS were at a significantly increased risk of reduction loss than those with MS (Table $2, p=0.005)$. The mean Neer score in the varus malunion group $\left(\mathrm{HSA}<120^{\circ}\right)$ at the last follow-up was $73.6 \pm 11.6$, versus $84.2 \pm 9.2$ in the non-varus malunion group (HSA $\geq$ $\left.120^{\circ}\right)(p<0.001$, Fig. 4$)$.

Linear regression showed that the Neer score was negatively associated with HSA change ( $2=0.647$, $p$ $<0.001$; Fig. 5). On univariate analyses, Neer type 4 fracture, the difference between the postoperative HSA (on the injured side) and that of the uninjured side (the $\triangle \mathrm{HSA}$ ), healing time, and the HSA change to the end of follow-up were all significantly associated with the Neer score (Table 3). On multivariate linear regression analysis, only healing time among the above four factors was excluded from the final model $(\mathrm{R} 2=0.692$, Table 4$)$.

\section{Discussion}

HSA loss was maximal from 1 to 3 months postoperatively, in agreement with the literature [8, 17]. The average healing time was 4.4 months; the HSA remained essentially unchanged after 6 months. Of fractures that did not heal within 3 months, significant differences were evident between the HSA in the immediate postoperative phase and the values measured over 1-3 months. We suspected that this might reflect early voluntary exercise. Most patients could endure residual pain 1 month after surgery and, after 2 months of functional exercise, limb function partially recovered. Hence, some patients may have commenced internal forward rotation, and even stretching and weight-bearing activities. Muscle action during such exercises might change the HSA. In addition, the biomechanical stability of the proximal humerus may be compromised by fracture-healing during this period. Primitive bone callus formation varies among 


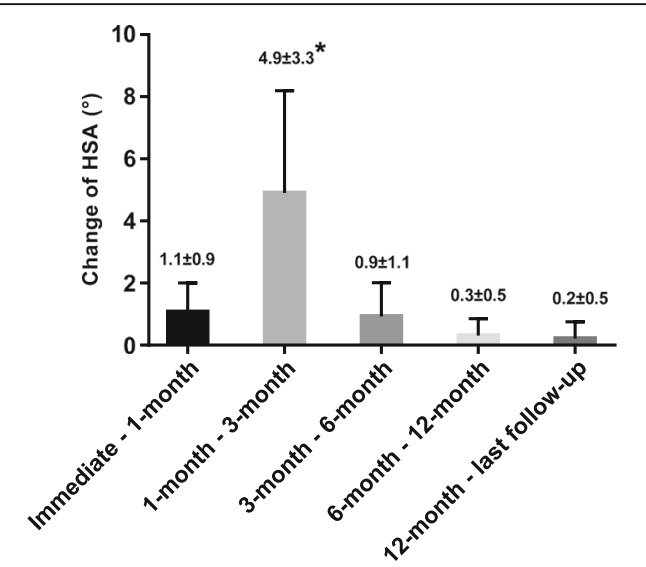

Immediate - 1-month

1-month - 3-month

3-month - 6-month

6-month - 12-month

12-month - last follow-up

Fig. 2 The change of HSA in each follow-up period. HSA, head-shaft angle; * indicate that most decrease of HSA occurs in the period of 1 to 3 months $(p<0.001)$

individuals; premature exercise may change the HSA but further research is required to confirm this.

The mean HSA of the with-MS group was significantly greater than that of the without-MS group at 3 months postoperatively $(p=0.003)$; MS was associated with less reduction loss. Overall, the reduction loss rate was significantly higher in the without-MS group $(p=0.005)$, consistent with other studies [1820].Jung et al. [21] reported that inadequate MS was an independent risk factor for reduction loss after surgery to treat PHFs. In the absence of MS, the fixed-angle screws must serve as perpendicular struts aiding the humeral head to resist varus displacement. Therefore, MS is important for maintenance of reduction in patients with PHFs; surgeons must maximally restore MS.

Earlier studies on the functional and radiological outcomes of PHFs reached conflicting conclusions. Yüksel et al. [22] found no relationship between the HSA and the Constant score (which measures

Table 2 Comparison of head-shaft angle and clinical outcomes between patient with medial support and without medial support

\begin{tabular}{|c|c|c|c|c|}
\hline & & With MS & Without MS & $p$ value \\
\hline \multirow[t]{6}{*}{ Mean HSA $\left(^{\circ}\right)$} & Immediate & $135.6 \pm 5.7$ & $135.9 \pm 5.0$ & 0.752 \\
\hline & 1-month & $134.2 \pm 5.8$ & $135.0 \pm 5.1$ & 0.412 \\
\hline & 3-month & $127.9 \pm 6.5$ & $131.5 \pm 6.7$ & 0.003 \\
\hline & 6-month & $126.7 \pm 6.3$ & $130.7 \pm 6.8$ & 0.001 \\
\hline & 12-month & $126.4 \pm 6.1$ & $130.3 \pm 6.7$ & $<0.001$ \\
\hline & Last follow-up & $126.2 \pm 6.1$ & $130.2 \pm 6.9$ & 0.001 \\
\hline \multirow[t]{5}{*}{ Neer's criteria } & & & & 0.056 \\
\hline & Excellent (> 89) & 14 & 28 & \\
\hline & Satisfactory (80-89) & 20 & 24 & \\
\hline & Unsatisfactory (70-79) & 14 & 12 & \\
\hline & Failure $(<70)$ & 10 & 0 & \\
\hline Neer's score & & $78.9 \pm 11.6$ & $86.3 \pm 7.2$ & 0.004 \\
\hline \multicolumn{5}{|l|}{ Complication } \\
\hline & Reduction loss & 14 & 4 & 0.005 \\
\hline & Varus malunion & 10 & 6 & 0.199 \\
\hline & Subacromial impingement & 0 & 2 & 0.175 \\
\hline & Delayed union & 2 & 2 & 0.920 \\
\hline & Reoperation & 2 & 0 & 0.134 \\
\hline
\end{tabular}




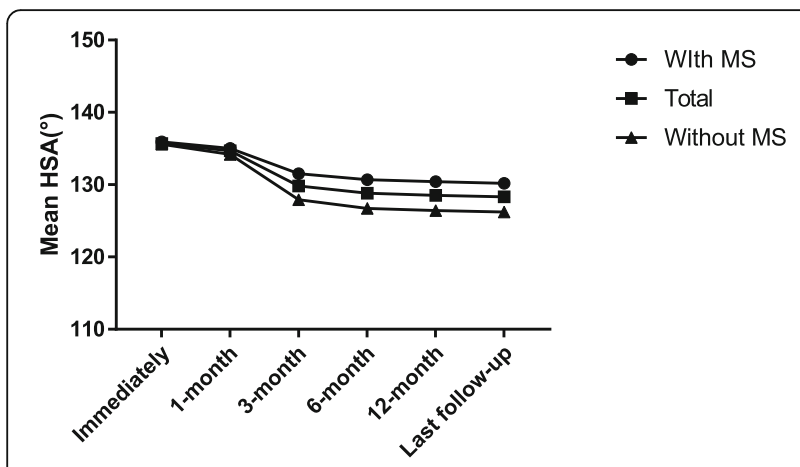

Fig. 3 The HSA trends during follow-up. HSA, head-shaft angle; MS, medial support

recovery); however, Bai et al. [23] reported that an HSA change $>10^{\circ}$ significantly reduced the score. We investigated the relationship between the HSA and functional recovery in PHF patients in whom locking plates were placed and found that HSA change was negatively associated with recovery. Court-Brown et al. [24] found no association between increasing varus angulation and shoulder function; Capriccioso et al. [25] reported that the initial surgical neck displacement (varus or valgus) did not significantly affect functional outcomes. Conversely, 16 of our patients experienced varus malunion; their mean Neer score was $73.6 \pm 11.6$, thus lower than that of non-varus malunion patients $(84.2 \pm 9.2, p<0.001)$. However, we would mention that three patients in the varus malunion group enjoyed excellent or satisfactory functional outcomes; all uninjured side HSAs were $<130^{\circ}$, and the Neer scores were 84,92 , and 83 . A previous study

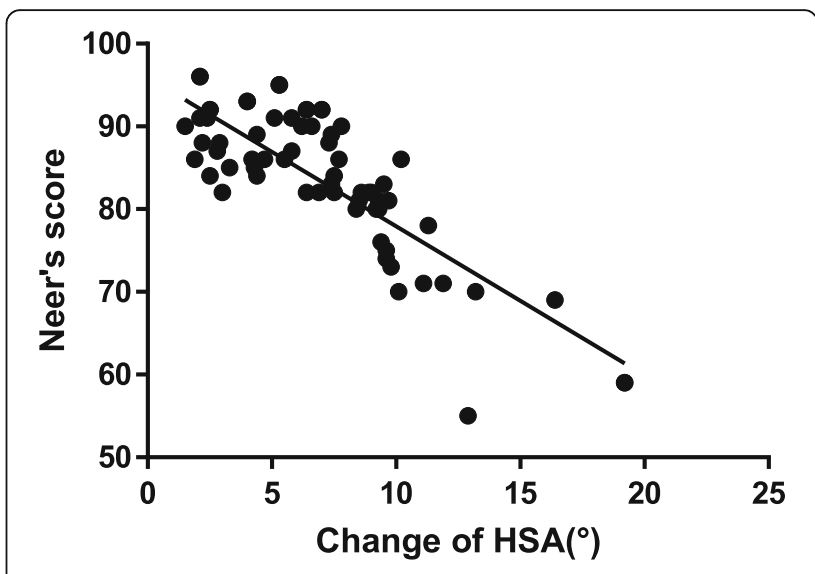

Fig. 5 Linear regression analysis of Neer's score and the HSA change to the end of follow-up. HSA, head-shaft angle

found no significant between-group difference in bilateral HSAs [26].Therefore, we used multivariable linear regression to control for confounding effects; we found that Neer type 4 fracture, the postoperative HSA difference between the injured and uninjured side, and the change in HSA to completion of follow-up may influence the Neer score. Similarly, a previous study reported that, in patients with twoand three-part fractures, the overall functional results were usually satisfactory; but this was not always the case in those with four-part fractures [27, 28]. We suggest that the latter fractures usually develop in osteoporotic patients, often associated with proximal fractures and medial metaphyseal comminution [29].We found that the postoperative HSA difference between the treated and uninjured side, and the

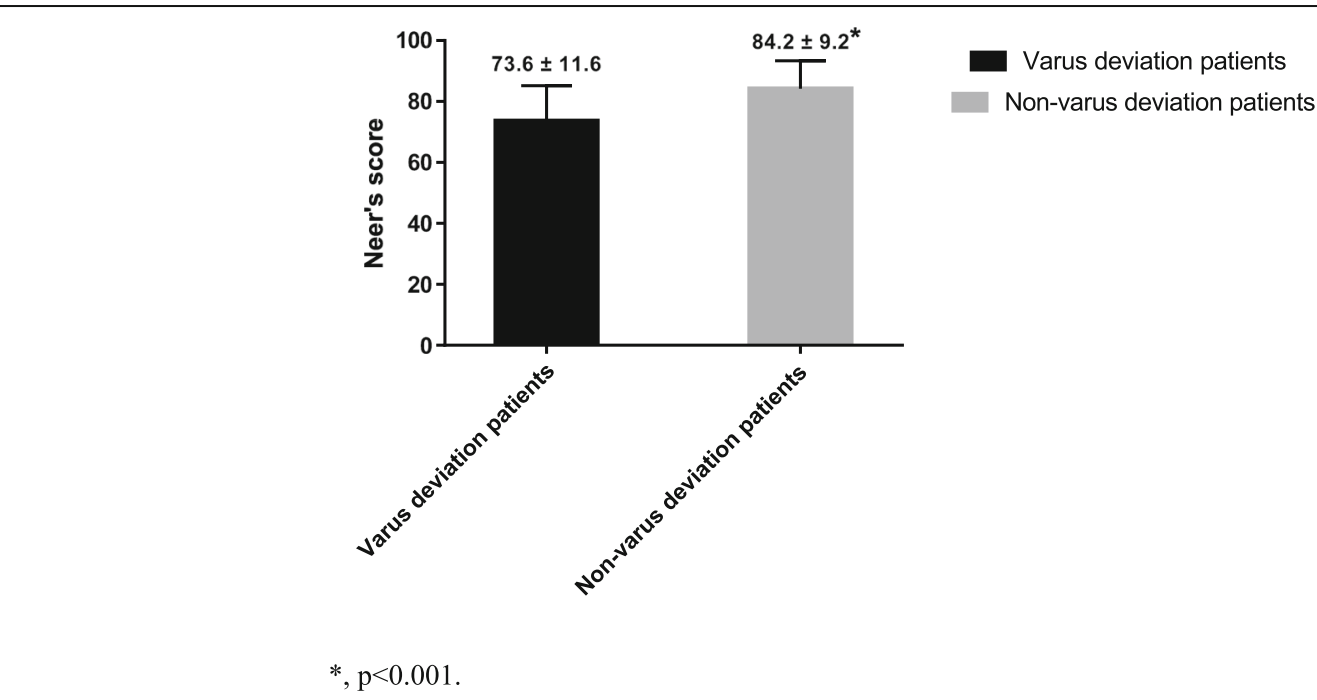

Fig. 4 The mean Neer's score in varus malunion and non-varus malunion patients. ${ }^{*}, p<0.001$ 
Table 3 Univariate association for each risk factor and Neer's score

\begin{tabular}{lll}
\hline Characteristics & RR $(95 \% \mathrm{Cl})$ & $\mathrm{p}$ value \\
\hline $\begin{array}{l}\text { Age (year) } \\
\text { Sex }\end{array}$ & $0.08(-0.04,0.19)$ & 0.212 \\
$\quad$ Female & Ref. & \\
$\quad$ Male & $0.25(-2.72,3.22)$ & 0.868 \\
Fracture type & & \\
2 & Ref. & 0.129 \\
3 & $2.42(0.69,5.52)$ & 0.041 \\
4 & $4.21(2.32,8.40)$ & 0.535 \\
Uninjured side HSA & $0.10(-0.21,0.40)$ & 0.245 \\
Postoperative HSA & $0.17(-0.11,0.44)$ & 0.003 \\
$\quad \Delta$ HSA & $-2.04(-3.36,-0.71)$ & 0.005 \\
Healing time (month) & $-1.54(-2.61,-0.47)$ & $<0.001$ \\
Change of HSA & $-1.80(-2.04,-1.56)$ & \\
\hline HSA, head-shaft angle; $\triangle H S A$, the difference between the postoperative HSA
\end{tabular}

$\mathrm{HSA}$, head-shaft angle; $\triangle \mathrm{HSA}$, the difference between the postoperative HSA (on the injured side) and that of the uninjured side; Change of HSA, the HSA change to the end of follow-up

change in HSA to completion of follow-up, were negatively associated with the Neer score. Thus, restoration of the native HSA afforded better functional recovery. We identified a trend toward improved function when it was possible to restore the HSA of the injured side to a value similar to that of the uninjured side. Also, we could not rule out an effect of reduction loss in patients for whom the pre-injury HSA was $<130^{\circ}$.

Our study had certain limitations. First, it used a retrospective design and the sample size relatively small; we also cannot exclude potential effects of unmeasured factors. Furthermore, we prescribed a general postoperative rehabilitation protocol, but some patients may have individualised needs regarding the timing of passive range-of-motion exercises; this could affect the clinical and radiographic outcomes. A future prospective study with a larger sample size is required to validate our findings.

Table 4 Multivariable linear regression model for Neer's score

\begin{tabular}{llll}
\hline Characteristics & Coefficient & $95 \% \mathrm{Cl}$ & $\mathrm{p}$ value \\
\hline Fracture type 4 & -4.31 & $-7.16,-1.46$ & 0.004 \\
$\Delta \mathrm{HSA}$ & -1.03 & $-1.84,-0.23$ & 0.014 \\
Healing time & 0.08 & $-0.74,0.89$ & 0.857 \\
Change of HSA & -1.70 & $-14.01,-1.93$ & $<0.001$ \\
\hline
\end{tabular}

$\mathrm{HSA}$, head-shaft angle; $\triangle \mathrm{HSA}$, the difference between the postoperative HSA (on the injured side) and that of the uninjured side; Change of HSA, the HSA change to the end of follow-up

\section{Conclusions}

Serial HSA changes were evident in PHF patients in whom locking plates had been inserted; it is essential to maintain reduction for $1-3$ months postoperatively. MS is important in this context and surgeons must maximally restore MS. Furthermore, the functional outcome tended to improve when the HSA of the injured side was restored to a value close to that of the uninjured side.

\section{Abbreviations \\ HSA: head-shaft angle; MS: medial support; PHF: Proximal humeral fracture; PHILO: The proximal humeral internal locking system; $\triangle H S A$ : the difference between the postoperative HSA (on the injured side) and that of the uninjured side}

\section{Acknowledgements}

JQW and BJJ contributed equally to this work and should be considered co-first authors. We thank all the colleagues for their valuable assistance during the implementation of this study.

Funding

This study was funded by Natural Science Foundation of Zhejiang Province (LY15H060009). Natural Science Foundation of Zhejiang Province was involved in the study design, data collection, data analysis, and preparation of the manuscript.

\section{Availability of data and materials}

The datasets analyzed in the study are available from the corresponding author on reasonable request.

\section{Authors' contributions}

YMZ: Study design, corresponding author; JQW: Analysis and interpretation of data, draft the manuscript; BJJ: Data collection and analysis; WJG: Supervise this study, critically revise the manuscript, and search the literature. All authors read and approved the final manuscript.

\section{Ethics approval and consent to participate}

This retrospective study was approved by the Ethics Committee of Second Affiliated Hospital of Wenzhou Medical University, and informed written consent for participation in the study was obtained.

\section{Consent for publication}

Not applicable.

\section{Competing interests}

The authors declare that they have no competing interest.

\section{Publisher's Note}

Springer Nature remains neutral with regard to jurisdictional claims in published maps and institutional affiliations.

Received: 24 August 2018 Accepted: 19 November 2018

Published online: 30 November 2018

\section{References}

1. Passaretti D, Candela V, Sessa P, Gumina S. Epidemiology of proximal humeral fractures: a detailed survey of 711 patients in a metropolitan area. J Shoulder Elb Surg. 2017;26(12):2117-24. https://doi.org/10.1016/j.jse.2017.05.029.

2. Hinds RM, Garner MR, Tran WH, Lazaro LE, Dines JS, Lorich DG. Geriatric proximal humeral fracture patients show similar clinical outcomes to non-geriatric patients after osteosynthesis with endosteal fibular strut allograft augmentation. J Shoulder Elb Surg. 2015;24(6):889-96. https://doi.org/10.1016/j.jse.2014.10.019.

3. Shulman BS, Egol KA. Open reduction internal fixation for proximal humerus fractures indications, techniques, and pitfalls. Bulletin of the Hospital for Joint Disease (2013). 2013;71(Suppl 2):54-9.

4. Jung WB, Moon ES, Kim SK, Kovacevic D, Kim MS. Does medial support decrease major complications of unstable proximal humerus fractures 
treated with locking plate? BMC Musculoskelet Disord. 2013;14:102. https:// doi.org/10.1186/1471-2474-14-102.

5. Gregory TM, Vandenbussche E, Augereau B. Surgical treatment of three and four-part proximal humeral fractures. Orthop Traumatol Surg Res. 2013;99(1 Suppl):S197-207. https://doi.org/10.1016/j.otsr.2012.12.006.

6. Clavert P, Adam P, Bevort A, Bonnomet F, Kempf JF. Pitfalls and complications with locking plate for proximal humerus fracture. J Shoulder Elb Surg. 2010;19(4):489-94. https://doi.org/10.1016/j.jse.2009.09.005.

7. Gonc U, Atabek M, Teker K, Tanriover A. Minimally invasive plate osteosynthesis with PHILOS plate for proximal humerus fractures. Acta Orthop Traumatol Turc. 2017:51(1):17-22. https://doi.org/10.1016/j.aott.2016.10.003.

8. Zhang L, Zheng J, Wang W, Lin G, Huang Y, Zheng J, Edem Prince GA, Yang $\mathrm{G}$. The clinical benefit of medial support screws in locking plating of proximal humerus fractures: a prospective randomized study. Int Orthop. 2011;35(11):1655-61. https://doi.org/10.1007/s00264-011-1227-5.

9. Krappinger D, Bizzotto N, Riedmann S, Kammerlander C, Hengg C, Kralinger FS. Predicting failure after surgical fixation of proximal humerus fractures. Injury. 2011;42(11):1283-8. https://doi.org/10.1016/j.injury.2011.01.017.

10. Konigshausen M, Kubler L, Godry H, Citak M, Schildhauer TA, Seybold D. Clinical outcome and complications using a polyaxial locking plate in the treatment of displaced proximal humerus fractures. A reliable system? Injury. 2012;43(2):223-31. https://doi.org/10.1016/j.injury.2011.09.024.

11. Buchler P, Farron A. Benefits of an anatomical reconstruction of the humeral head during shoulder arthroplasty: a finite element analysis. Clinical biomechanics (Bristol, Avon). 2004;19(1):16-23.

12. Neer CS 2nd. Displaced proximal humeral fractures. I. Classification and evaluation. J Bone Joint Surg Am. 1970;52(6):1077-89.

13. Agudelo J, Schurmann M, Stahel P, Helwig P, Morgan SJ, Zechel W, Bahrs C, Parekh A, Ziran B, Williams A, Smith W. Analysis of efficacy and failure in proximal humerus fractures treated with locking plates. J Orthop Trauma. 2007;21(10):676-81. https://doi.org/10.1097/BOT.0b013e31815bb09d.

14. Greiner S, Kaab MJ, Haas NP, Bail HJ. Humeral head necrosis rate at midterm follow-up after open reduction and angular stable plate fixation for proximal humeral fractures. Injury. 2009;40(2):186-91. https://doi.org/10. 1016/j.injury.2008.05.030.

15. Owsley KC, Gorczyca JT. Fracture displacement and screw cutout after open reduction and locked plate fixation of proximal humeral fractures [corrected]. J Bone Joint Surg Am. 2008;90(2):233-40. https://doi.org/10.2106/jbjs.f.01351.

16. Neer CS 2 nd. Four-segment classification of proximal humeral fractures: purpose and reliable use. J Shoulder Elb Surg. 2002;11(4):389-400. https:// doi.org/10.1067/mse.2002.124346.

17. Pawaskar AC, Lee KW, Kim JM, Park JW, Aminata IW, Jung HJ, Chun JM, Jeon $\mathrm{IH}$. Locking plate for proximal humeral fracture in the elderly population: serial change of neck shaft angle. Clin Orthop Surg. 2012;4(3):209-15. https://doi.org/10.4055/cios.2012.4.3.209.

18. Gardner MJ, Weil Y, Barker JU, Kelly BT, Helfet DL, Lorich DG. The importance of medial support in locked plating of proximal humerus fractures. J Orthop Trauma. 2007;21(3):185-91. https://doi.org/10.1097/BOT.0b013e3180333094.

19. Erdogan M, Desteli EE, Imren Y, Uzturk A, Kilic M, Sezgin H. The effect of inferomedial screw on postoperative shoulder function and mechanical alignment in proximal humerus fractures. Eur J Orthop Surg Traumatol. 2014;24(7):1055-9. https://doi.org/10.1007/s00590-013-1391-y.

20. Gadea F, Favard L, Boileau P, Cuny C, d'Ollone T, Saragaglia D, Sirveaux F. Fixation of 4-part fractures of the proximal humerus: can we identify radiological criteria that support locking plates or IM nailing? Comparative retrospective study of 107 cases. Orthop Traumatol Surg Res. 2016;102(8): 963-70. https://doi.org/10.1016/j.otsr.2016.09.015.

21. Jung SW, Shim SB, Kim HM, Lee JH, Lim HS. Factors that influence reduction loss in proximal Humerus fracture surgery. J Orthop Trauma. 2015;29(6):27682. https://doi.org/10.1097/bot.0000000000000252

22. Yuksel HY, Yilmaz S, Aksahin E, Celebi L, Muratli HH, Bicimoglu A. The results of nonoperative treatment for three- and four-part fractures of the proximal humerus in low-demand patients. J Orthop Trauma. 2011;25(10):588-95. https://doi.org/10.1097/BOT.0b013e318210ea56.

23. Bai L, Fu ZG, Wang TB, Chen JH, Zhang PX, Zhang DY, Jiang BG. Radiological evaluation of reduction loss in unstable proximal humeral fractures treated with locking plates. Orthop Traumatol Surg Res. 2014; 100(3):271-4. https://doi.org/10.1016/j.otsr.2013.12.024.

24. Court-Brown CM, McQueen MM. The impacted varus (A2.2) proximal humeral fracture: prediction of outcome and results of nonoperative treatment in 99 patients. Acta Orthop Scand. 2004;75(6):736-40.
25. Capriccioso CE, Zuckerman JD, Egol KA. Initial varus displacement of proximal humerus fractures results in similar function but higher complication rates. Injury. 2016;47(4):909-13. https://doi.org/10.1016/j.injury.2016.01.021.

26. Malavolta EA, Assuncao JH, Pagotto RA, Avelino RL, Gracitelli ME, Pereira CA, Jacomo AL, Ferreira Neto AA. The rotation of the humeral head does not alter radiographic evaluation of the head-shaft angle. J Shoulder Elb Surg. 2016;25(4):543-7. https://doi.org/10.1016/j.jse.2015.09.026

27. Fankhauser F, Boldin C, Schippinger G, Haunschmid C, Szyszkowitz R. A new locking plate for unstable fractures of the proximal humerus. Clin Orthop Relat Res. 2005;430:176-81.

28. Thanasas C, Kontakis G, Angoules A, Limb D, Giannoudis P. Treatment of proximal humerus fractures with locking plates: a systematic review. J Shoulder Elb Surg. 2009;18(6):837-44. https://doi.org/10.1016/j.jse.2009.06.004.

29. Sohn HS, Shin SJ. Minimally invasive plate osteosynthesis for proximal humeral fractures: clinical and radiologic outcomes according to fracture type. J Shoulder Elb Surg. 2014;23(9):1334-40. https://doi.org/10.1016/j.jse.2013.12.018.
Ready to submit your research? Choose BMC and benefit from:

- fast, convenient online submission

- thorough peer review by experienced researchers in your field

- rapid publication on acceptance

- support for research data, including large and complex data types

- gold Open Access which fosters wider collaboration and increased citations

- maximum visibility for your research: over $100 \mathrm{M}$ website views per year

At BMC, research is always in progress.

Learn more biomedcentral.com/submissions 